\title{
Transmissão Intergeracional de Práticas Educativas Parentais: Evidências Empíricas ${ }^{1}$
}

\author{
Angela Helena Marin ${ }^{2}$ \\ Universidade do Vale do Rio dos Sinos \\ Gabriela Dal Forno Martins \\ Ana Paula Corrêa de Oliveira Freitas \\ Isabela Machado Silva \\ Rita de Cássia Sobreira Lopes \\ Cesar Augusto Piccinini \\ Universidade Federal do Rio Grande do Sul
}

\begin{abstract}
RESUMO - O estudo investigou a transmissão intergeracional das práticas educativas parentais em 30 mães e 22 pais, cujo primeiro filho tinha 3 anos. Os participantes responderam a entrevistas sobre as práticas educativas recebidas dos genitores e as utilizadas com o filho. Análises quantitativa e de conteúdo foram realizadas, categorizando-se as práticas em indutivas, coercitivas e não interferência. Os resultados indicaram tanto a manutenção das práticas recebidas, sejam elas indutivas, coercitivas ou de não interferência, como mudanças no tipo de prática utilizada devido a características do casal e da criança. Discute-se que as práticas educativas envolvem um processo dinâmico entre pais e filhos, sendo a transmissão intergeracional não linear e influenciada por fatores que não apenas a reprodução de padrões aprendidos.
\end{abstract}

Palavras-chave: práticas educativas parentais, padrões intergeracionais, relações familiares, relações pais-criança

\section{Transmission of Childrearing Practices between Generations: Empirical Evidence}

\begin{abstract}
This study investigated the transmission between generations of childrearing practices of 30 mothers and 22 fathers, whose first child was 3 years old. Participants were interviewed about childrearing practices they had themselves received from their parents and those they used with their children. Quantitative and content analyses were realized with childrearing practices categorized as inductive, coercive and non-interfering. Results showed continuity of received practices, whether they were inductive, coercive or non-interfering, as well as changes in the used practices due to characteristics of the couple or the child. Childrearing practices seem to comprise a dynamic process between parents and children, with a nonlinear transmission between generations, and affected by factors other than reproduction of learned patterns.
\end{abstract}

Keywords: childrearing practices, intergenerational patterns, family relations, parent-child relations

O conceito de família tem passado por constantes modificações decorrentes das transformações sociais e culturais da sociedade pós-moderna (Fonseca, 2005), bem como a concepção de criança e seu espaço na família (Biasoli-Alves, 1997). Todavia, por se tratar do primeiro meio social do qual o indivíduo participa, a família ainda tem entre suas tarefas fundamentais o processo de socialização, através do qual a criança deve adquirir comportamentos, habilidades e valores apropriados à sociedade em que está inserida (Biasoli-Alves, 1997; Nichols \& Schwartz, 1998; Steinberg, 2000).

1 Os autores agradecem ao bolsista Ricardo Bertazzo Ghilardi pelo auxílio na fase de codificação dos dados.

2 Endereço para correspondência: Unisinos - Campus São Leopoldo. Av. Unisinos, 950. Centro de Ciências da Saúde - sala 2A-108. Bairro Cristo Rei. São Leopoldo, RS. CEP: 93.022-000. E-mail: angelahm@unisinos.br
Para cumprir o papel de agentes de socialização dos filhos $^{3}$, os pais ${ }^{4}$ se utilizam de diversas estratégias e técnicas, chamadas práticas educativas parentais (Hoffman, 1975, 1994; Newcombe, 1999). Hoffman (1975, 1979, 1994) propõe a classificação das práticas educativas parentais em duas categorias distintas: as estratégias indutivas e as estratégias de força coercitiva. Ambos os tipos de estratégia têm por função comunicar à criança o desejo dos pais de que ela mantenha ou modifique seu comportamento (Alvarenga \& Piccinini, 2001).

3 Os termos "filho" e "filhos" serão utilizados, no presente estudo, para as situações envolvendo tanto crianças do sexo masculino como feminino.

4 No presente estudo, o termo "pais" será utilizado para as situações envolvendo mãe e pai, à exceção daquelas em que esses termos encontram-se discriminados, ao passo que o termo "pai" no singular será usado para designar apenas o pai. 
As práticas indutivas caracterizam-se por direcionar a atenção da criança para as consequências de seu comportamento às outras pessoas e para as demandas lógicas da situação, ao invés das consequências punitivas para ela mesma (Hoffman, 1975, 1994). Dessa forma, a criança adquire compreensão das implicações de suas ações e dos motivos que justificam a necessidade de mudança no seu comportamento (Alvarenga \& Piccinini, 2003). Práticas desse tipo são caracterizadas por explicações sobre as consequências do comportamento da criança para os outros e para si mesma, esclarecimentos sobre regras, princípios, valores, advertências morais e apelos ao orgulho da criança e ao amor que ela sente pelos pais (Grusec \& Lytton, 1988).

Em contrapartida, as práticas coercitivas caracterizam-se pelo uso da aplicação de força direta e do poder dos pais (Hoffman, 1975, 1994). Incluem punição física e privação de privilégios ou ameaças, compelindo a criança a adequar o seu comportamento a determinadas situações e às reações punitivas dos pais. Para esse autor, as estratégias coercitivas provocam o controle do comportamento da criança baseado na ameaça de sanções externas e intensificam a percepção de valores e do padrão de ação moral como externos. A coercitividade dos pais pode produzir na criança emoções intensas, tais como medo, raiva e ansiedade, que tendem a reduzir ainda mais a possibilidade de a criança compreender a situação e a necessidade da modificação de seu comportamento.

Vários aspectos podem operar como determinantes das práticas educativas parentais. Uma vez entendendo as relações que se estabelecem no sistema familiar como sendo recíprocas, tanto características das crianças como dos genitores exercem importante influência sobre os processos de socialização (Belsky, 1984; Biasoli-Alves, 1997). Em se tratando das diversas características dos genitores que podem influenciar as suas práticas educativas, é importante considerar os aspectos intergeracionais, que dizem respeito à criação que eles próprios receberam de seus pais ao longo de seu desenvolvimento.

A ideia de que o exercício da parentalidade pode sofrer influências intergeracionais tem sido defendida por diferentes linhas teóricas, como a teoria familiar sistêmica, a teoria da aprendizagem social e a teoria do apego. Em decorrência de suas especificidades epistemológicas, essas linhas diferem entre si no que tange aos mecanismos apresentados para a justificação dessa influência, mas apresentam em comum a ideia de que determinados padrões interacionais seriam assimilados a partir da convivência com a família (Belsky, Conger, \& Capaldi, 2009). A teoria familiar sistêmica destaca como os padrões presentes na família de origem levam à construção de modelos (Ângelo, 1995), conscientes ou não, sobre o que deve ser seguido ou evitado nas relações posteriores (Falcke, Wagner, \& Mossman, 2005). Esses padrões, muitas vezes, embasam-se em mitos (Falcke \& Wagner, 2005; Miermont, 1994) ou segredos familiares (Imber-Black, 1994) transmitidos através das gerações, assim como em um processo de delegação familiar acerca do que é esperado de cada membro da família (Boszormenyi-Nagy \& Spark, 1973/2008; Miermont, 1994). Já na teoria da aprendizagem social, assinalam-se os aspectos comportamentais aprendidos, os quais compreendem o reforço de certos comportamentos do próprio indivíduo e a modelagem, que consiste na observação de comportamentos emitidos por outras pessoas (Bandura, 1977). Por fim, a teoria do apego enfatiza como as experiências iniciais com a figura de apego levam à construção de modelos operacionais a respeito de si mesmo e dos outros, que influenciarão as relações futuras (Bowlby, 1982/2001) e servirão como base para a criação dos filhos através da busca pela replicação ou pela correção de experiências prévias (Byng-Hall, 1990).

Estudos empíricos realizados a partir de diferentes métodos (retrospectivos e prospectivos; utilizando entrevistas, observações ou escalas) têm corroborado a existência de continuidade intergeracional no que diz respeito a diferentes dimensões da parentalidade (Bailey, Hill, Oesterle, \& Hawkins, 2009; Conger, Belsky, \& Capaldi, 2009; Neppl, Conger, Scaramella, \& Ontai, 2009; Weber, Selig, Bernardi, \& Salvador, 2006). De acordo com Conger et al. (2009), embora os resultados obtidos por esses estudos demonstrem efeitos entre leves e moderados, os mesmos têm se mostrado consistentes em diferentes populações, independente do método utilizado, o que sugere que, de fato, há uma conexão entre a parentalidade em diferentes gerações.

Conforme destacaram Belsky et al. (2009), evidências dessa continuidade são oriundas de estudos que investigaram a transmissão da violência contra os filhos, havendo, nesse campo, um predomínio de pesquisas voltadas à transmissão de práticas coercitivas (Bailey et al., 2009; Kerr, Capaldi, Pears, \& Owen, 2009). Nesse contexto, estudos quantitativos realizados nos Estados Unidos e no Brasil constataram a continuidade no uso de comportamentos agressivos, tais como críticas, rejeição aos interesses do outro, ameaças e agressão física (Bailey et al., 2009; Conger, Neppl, Kim, \& Scaramella, 2003; Kim, 2009; Neppl et al., 2009), assim como de práticas disciplinares consideradas inconsistentes (Capaldi, Pears, Patterson, \& Owen, 2003) ou negligentes (Vitali, 2004). De forma semelhante, Oliveira et al. (2002), em estudo retrospectivo do qual participaram 50 mães brasileiras que responderam a uma série de escalas, verificaram a transmissão de um estilo parental autoritário. Hennig (2008), em uma pesquisa realizada com 80 mães e pais também brasileiros, que responderam a escalas referentes às suas memórias de cuidados recebidos na infância e ao seu estilo parental, constatou que conflito com os próprios pais na infância, rejeição por parte destes e pouca afetividade na relação mostraram-se associados a questões como baixa monitoria positiva, maior ocorrência de abuso e uso de punições inconsistentes na criação dos filhos.

Alguns desses estudos, no entanto, têm demonstrado que diferentes aspectos podem influenciar essa transmissão. Oliveira et al. (2002) constataram, por exemplo, que a presença de conflito conjugal mediaria a transmissão de um estilo autoritário, ou seja, a utilização de práticas autoritárias por parte da mãe contribuiria para a ocorrência de conflitos no relacionamento conjugal de sua filha, os quais favoreceriam a adoção de práticas autoritárias por parte dessa filha junto a seus próprios filhos. O nível socioeconômico familiar também tem sido indicado como podendo interferir no uso das práticas educativas parentais (Bailey et al. 2009; Conger et al., 2009). Nesse sentido, mudanças socioeconômicas entre as gerações poderiam influenciar a transmissão das práticas educativas, uma vez que na medida em que uma nova ge- 
ração vivencia diferentes experiências ligadas ao trabalho e a educação, estas podem transformar seus valores sobre a educação de crianças e consequentemente suas práticas educativas (Benincá \& Gomes, 1998; Weber et al., 2006).

Outros estudos internacionais, caracterizados por uma abordagem prospectiva e pela participação de três gerações de famílias acompanhadas por um longo período de tempo, com a utilização de diferentes métodos (escalas, observações e entrevistas), destacaram que os diversos tipos de práticas parentais recebidos e utilizados tenderiam a influenciar a ocorrência de certos tipos de comportamento. Por exemplo, Capaldi et al. (2003) verificaram que a utilização de práticas severas, inconsistentes ou frouxas favoreceria o desenvolvimento de comportamentos antissociais, os quais, por sua vez, contribuiriam para a possibilidade de parentalidade inadequada (Hops, Davis, Leve, \& Sheeber, 2003). Contudo, para que os problemas de comportamento medeiem a continuidade de uma parentalidade severa, é necessário que se estendam para além da adolescência e estejam presentes quando esses jovens pais chegarem à idade adulta (Neppl et al., 2009).

Embora em menor frequência, estudos quantitativos internacionais também investigaram a transmissão de uma parentalidade considerada positiva, marcada por características que favoreceriam o desenvolvimento dos filhos, tais como supervisão parental, envolvimento entre pais e filhos, relações familiares de qualidade, expressão de emoções positivas e regras familiares consistentes (Belsky, Jaffee, Sligo, Woodward, \& Silva, 2005; Kerr et al., 2009; Shaffer, Burt, Obradovic, Herbers, \& Masten, 2009). Belsky et al. (2005) acompanharam mais de 200 homens e mulheres desde os 3 anos até o período em que seus próprios filhos estavam com essa idade, utilizando observações, entrevistas e escalas. Os autores verificaram que mães que, ao longo do seu desenvolvimento, receberam uma educação menos autoritária, que vivenciaram relacionamentos familiares de boa qualidade e que mantiveram com seus pais relações marcadas pela confiança e comunicação, apresentaram, com maior frequência, uma parentalidade do tipo afetiva, sensível e estimulante. Resultados semelhantes foram obtidos em um estudo nacional. Hennig (2008) constatou que a presença de memórias de relações afetivas na infância mostrou-se relacionada a práticas consideradas positivas, tais como supervisão parental e comportamento moral.

No entanto, assim como foi constatado em estudos referentes a práticas consideradas inadequadas, alguns deles destacaram fatores que podem mediar essa influência. Dessa forma, o uso de práticas parentais positivas favoreceria, nos filhos, o desenvolvimento de características que, no futuro, contribuiriam para que os mesmos também utilizassem práticas positivas na criação de seus próprios filhos. Investigações internacionais que consideraram pelo menos três gerações familiares destacaram que a transmissão da parentalidade construtiva não ocorre diretamente, mas há o desenvolvimento de características como autoestima e habilidades sociais e acadêmicas, que favorecem os relacionamentos futuros (Kerr et al., 2009; Shaffer et al., 2009).

De acordo com Neppl et al. (2009), embora existam evidências de que, de fato, existe uma continuidade intergeracional no que diz respeito à parentalidade, o conhecimento sobre como se dá essa transmissão ainda é limitado. Visto que as experiências vivenciadas durante a própria criação não são inevitavelmente repetidas, torna-se necessário estar atento aos diversos fatores que podem influenciar essa relação (Belsky et al., 2009). A esse respeito, Weber et al. (2006) sugerem que a descontinuidade de práticas educativas pode estar relacionada a ideia de quebra dos padrões familiares e à maior divulgação de informações científicas a respeito da criação dos filhos. Nesse sentido, a geração atual tem sido descrita como mais crítica e atenta a questões como liberdade de escolha e opinião, afetividade, autonomia e realização pessoal, modificando padrões relacionais presentes nas gerações precedentes. Outros fatores que poderiam influenciar essa continuidade ou descontinuidade seriam a aprendizagem de práticas ou habilidades parentais junto a outras figuras que não os próprios pais, tais como os avós ou, até mesmo, os cônjuges (Capaldi et al., 2003) e a forma como as pessoas avaliam a maneira como foram criadas (Shaffer et al., 2009).

A partir desses estudos é possível perceber a relevância do tema intergeracionalidade das práticas educativas parentais, inclusive sob uma óptica preventiva (Capaldi et al., 2003). No entanto, a grande diversidade de fatores que podem influenciar esse processo sugere a importância de que, para além da investigação sobre os padrões grupais de estabilidade e mudança das práticas educativas entre gerações, se estude as particularidades de cada família. Tal análise pode revelar fatores individuais associados ao processo de transmissão, como, por exemplo, a forma como cada um elabora e assimila como foi educado e como irá educar. Assim, neste trabalho, investigou-se, em um primeiro momento, a intergeracionalidade das práticas educativas paternas e maternas entre as gerações, considerando o grupo como um todo, e, em um segundo momento, a intergeracionalidade dessas práticas em cada família. Para tanto, utilizaram-se métodos quantitativos e qualitativos e se partiu da definição de práticas educativas proposta por Hoffman $(1975,1994)$. Acredita-se que a utilização de categorias baseadas na literatura tende a favorecer a integração dos resultados obtidos em diferentes estudos, assim como entre teoria e pesquisa.

\section{Método}

\section{Participantes}

Participaram deste estudo 30 mães e 22 pais, cujo primeiro filho tinha 3 anos de idade. As mães apresentavam idade média de 27 anos $(\mathrm{SD}=5,81)$ e os pais de 29 anos $(\mathrm{SD}=7,53)$. A escolaridade das mães variou entre o ensino fundamental incompleto (10\%) e completo (10\%), o ensino médio incompleto $(16,6 \%)$ e completo $(26,6 \%)$ e o superior incompleto (16,8\%) e completo (20\%). Já a escolaridade dos pais variou entre o ensino fundamental incompleto $(20 \%) \mathrm{e}$ completo (13\%), o ensino médio incompleto (7\%) e completo (27\%), o superior incompleto $(20 \%)$ e completo $(10 \%)$ e pós-graduação (3\%). Em relação ao nível socioeconômico, 17\% das famílias pertenciam ao nível baixo, $26 \%$ ao nível médio baixo, $20 \%$ ao médio, $17 \%$ ao médio alto e $20 \%$ ao alto. No que diz respeito ao sexo da criança, $30 \%$ eram meninas e $70 \%$ meninos. Quanto à situação conjugal, $80 \%$ tinham 
companheiro(a), 17\% eram solteiros(as) e 3\% separados(as). Todos os participantes faziam parte do Estudo Longitudinal de Porto Alegre: da Gestação à Escola - ELPA (Piccinini, Tudge, Lopes, \& Sperb, 1998/2009), que foi aprovado pela Comissão de Pesquisa e Ética em Saúde do Hospital de Clínicas de Porto Alegre (CPPG/HCPA). Esse estudo iniciou acompanhando 81 primigestas e seus bebês nascidos a termo, pertencentes a várias configurações familiares (nucleares, uniparentais ou recasadas), e envolveu várias fases de coletas de dados desde a gestação até os 8 anos das crianças. Seu objetivo foi investigar aspectos subjetivos e comportamentais das interações iniciais pai-mãe-bebê e o impacto de fatores iniciais do desenvolvimento nas interações familiares, no comportamento social de crianças pré-escolares e na transição para a escola de ensino fundamental.

\section{Materiais e Procedimentos}

De acordo com as fases de coleta do projeto ELPA, aos 36 meses de vida das crianças, as famílias foram contatadas para agendar uma visita em suas residências, quando se atualizaram as informações referentes aos dados sociodemográficos dos participantes e se aplicaram diferentes instrumentos de pesquisa separadamente para as mães e os pais participantes.

No presente estudo utilizou-se a Entrevista sobre o Passado dos Pais (Tudge, 1994), a partir da qual se obtiveram informações sobre a infância dos participantes e as práticas educativas que receberam de seus genitores. Para fins de análise, foram consideradas as perguntas referentes a como você descreveria a maneira como seus pais o criaram? Quais eram os principais objetivos de seus pais em relação a você? Que estratégias eles usavam para alcançar tais objetivos? Também foram utilizados os dados da Entrevista sobre Estratégias Disciplinares (Tudge, 1994), utilizada para a análise das práticas educativas que as mães e os pais participantes utilizavam com seus próprios filhos. Dessa entrevista, foram consideradas as seguintes questões: quais técnicas disciplinares você acredita que sejam mais apropriadas e menos apropriadas quando se educa um filho(a)? Quão obediente é seu filho(a)? O que você faz quando ele/ ela [criança] é desobediente ou faz algo que você não queria que ele/ela [criança] fizesse?

\section{Resultados}

As respostas dos participantes às diferentes questões da entrevista foram transcritas literalmente e analisadas através da análise de conteúdo (Bardin, 1977; Laville \& Dione, 1999). Para tanto, utilizou-se um sistema de categorias pré-definidas, baseado em Hoffman (1975, 1994), com adaptações feitas por autores do presente estudo (Alvarenga \& Piccinini, 2003; Marin, Piccinini, \& Tudge, 2011), o qual propõe uma classificação das práticas educativas em três categorias. A primeira delas, práticas indutivas, refere-se às subcategorias negocia/troca, explica/fala, explica baseado em convenção/consequência, organiza o ambiente/forma hábito e comanda sem coerção. A segunda categoria, práticas coercitivas, reúne as subcategorias punição, ameaça, coação física e punição física. Por fim, a terceira, práticas de não interferência, envolve as subcategorias não se intromete, segue o ritmo da criança e cede à vontade da criança. Detalhes da definição operacional desse sistema são apresentados em Marin (2009).

No presente estudo, optou-se, ainda, em classificar, em uma categoria à parte, os relatos em que as mães e os pais se referiam ao uso combinado de práticas indutivas e coercitivas. Nessa categoria, foram incluídos os relatos frequentes sobre tentativas das mães e dos pais de utilizarem uma determinada prática, comumente indutiva, a qual, se não obtivesse sucesso, era procedida de uma coercitiva. Essa categoria foi denominada indutiva/coercitiva. Outras combinações entre as categorias de práticas educativas (por exemplo: indutivas/ não interferência) não foram consideradas, tendo em vista que foram pouco relatadas pelos pais.

Para fins de análise, dois pesquisadores leram repetidas vezes todas as respostas às questões das entrevistas destacadas acima e assinalaram as práticas mencionadas pelas mães e pelos pais. Posteriormente, $20 \%$ dessas práticas foram utilizadas para se estabelecer o índice de fidedignidade entre os dois codificadores na classificação das práticas dentre as quatro categorias mencionadas acima, que atingiu $71 \%$ de concordância. Por fim, todas as práticas foram classificadas entre as categorias.

Buscando responder aos objetivos do estudo, foram realizados três conjuntos de análise. $\mathrm{O}$ primeiro considerou o grupo de mães e pais como um todo. Calcularam-se as frequências e proporções totais em cada categoria de prática, comparando-se as proporções de práticas recebidas e utilizadas, sendo que essa análise também foi realizada separando-se as mães e os pais participantes. A comparação foi realizada através de um teste não paramétrico de comparação de proporções (teste Z), uma vez que as frequências absolutas para práticas recebidas e utilizadas resultaram de respostas a perguntas de naturezas diferentes e, por isso, poderiam gerar resultados enviesados.

O segundo conjunto de análises considerou a transmissão intergeracional caso a caso, visando verificar se pais que receberam predominantemente determinado tipo de prática educativa em sua criação tendiam a repetir o mesmo modelo com seus próprios filhos. Sempre que uma prática educativa (conforme as mesmas categorias já descritas) representasse pelo menos $70 \%$ do total de práticas citadas por cada participante (separadamente para práticas recebidas e utilizadas), considerou-se predomínio da respectiva prática. Quando não houve qualquer predomínio, denominou-se sem predominância de práticas. A partir das variáveis criadas, foram realizadas análises com o teste qui-quadrado para examinar a associação entre as práticas predominantes recebidas e utilizadas, de modo que resultados estatisticamente significativos indicariam haver uma associação entre a distribuição de práticas recebidas e utilizadas e, portanto, indícios de transmissão intergeracional.

Por fim, em um terceiro momento realizou-se uma análise qualitativa das vinhetas das práticas educativas e de outros relatos parentais que se referissem à sua relação com os próprios pais e que remetessem à transmissão intergeracional das práticas, buscando ampliar a compreensão de outros aspectos que poderiam estar relacionados à transmissão. Os casos 
Tabela 1. Porcentagem e Frequências de Práticas Educativas Recebidas e Utilizadas

\begin{tabular}{lccccr}
\hline & \multicolumn{3}{c}{ Recebidas } & \multicolumn{3}{c}{ Utilizadas } & $\mathbf{Z}$ \\
& $\%$ & $\mathrm{f}$ & $\%$ & $\mathrm{~F}$ & \\
\hline Indutivas & 40 & 43 & 26 & 62 & $2,52^{*}$ \\
Coercitivas & 52 & 56 & 60 & 144 & 1,21 \\
Indutivas/coercitivas & 3,5 & 4 & 13,5 & 34 & $2,7 * *$ \\
Não interferência & 4,5 & 5 & 0,5 & 1 & $2,35^{*}$ \\
Total & 100 & 108 & 100 & 241 & \\
\hline
\end{tabular}

$* \mathrm{p}<0,05 ; * \mathrm{p}<0,01$

foram classificados em dois grupos: a) aqueles em que houve semelhança entre as práticas predominantemente recebidas e as utilizadas e b) aqueles em que não houve semelhança entre as mesmas.

Os resultados derivados das análises propostas acima serão apresentados separadamente em três seções.

\section{Práticas Educativas Recebidas e Utilizadas pelas Mães e pelos Pais}

Considerando os 52 participantes do estudo, obteve-se um total absoluto de 108 práticas recebidas e 241 práticas utilizadas. A Tabela 1 apresenta as porcentagens e frequências das práticas educativas nas diferentes categorias, assim como o valor $\mathrm{Z}$ resultante da comparação das proporções de práticas recebidas e utilizadas.

Os participantes (mães e pais) relataram ter recebido de seus pais com maior frequência as práticas coercitivas (52\%), seguidas das indutivas (40\%), e com menor frequência a combinação de indutivas/coercitivas $(3,5 \%)$ e as práticas de não interferência (4,5\%). Tendência semelhante ocorreu em relação às práticas utilizadas com os filhos, pois foram mais frequentemente relatadas as práticas coercitivas $(60 \%)$ do que as indutivas (26\%). Já a combinação de práticas indutivas/ coercitivas foi mais indicada (13\%) entre as utilizadas. Com base no teste de comparação de proporções entre as gerações cabe destacar a diferença significativa revelada na proporção de práticas indutivas $(\mathrm{p}<0,05)$, indicando a presença mais frequente dessas práticas na educação recebida pelos próprios pais do que seu uso com os filhos. O mesmo ocorreu com a categoria não interfere, que, apesar da baixa frequência, foi mais relatada como recebida do que utilizada $(p<0,05)$. Por fim, diferenças significativas foram também verificadas na categoria indutivas/coercitivas $(p<0,01)$, indicando o uso mais frequente dessas práticas com os filhos, quando comparado com as práticas que receberam de seus próprios pais.

A Tabela 2 apresenta separadamente as porcentagens e frequências das práticas educativas das mães e dos pais para cada categoria. As mães relataram 218 práticas educativas (30\% recebidas e 70\% utilizadas). Já os pais relataram 131 práticas educativas ( $34 \%$ recebidas e $66 \%$ utilizadas). Como pode ser visto na tabela, a distribuição de práticas recebidas e utilizadas foi semelhante para as mães e os pais.

Pelo relato das mães, elas receberam de seus pais mais práticas coercitivas $(53 \%)$ e também as utilizavam com seus filhos $(56 \%)$. Da mesma forma, elas relataram que receberam menos práticas indutivas $(41 \%)$ e também as usavam menos com seus filhos (30\%). Já a combinação de indutivas/coercitivas foi pouco relatada como recebida (3\%), mas foi mais utilizada com seus filhos (13\%). As comparações entre proporções de práticas recebidas e utilizadas pelas mães revelaram uma diferença significativa somente para a combinação de indutivas/coercitivas $(p<0,05)$, indicando o aumento do uso dessas práticas pelas mães com seus filhos.

O relato dos pais revela muitas semelhanças com o das mães, quando mencionaram que receberam mais práticas coercitivas (50\%) e utilizavam com seus filhos ainda mais esse tipo de prática (65\%). Quanto às práticas indutivas, relataram ter recebido mais ( $38 \%$ ) do que utilizavam com seus filhos (18\%). Já a combinação de indutivas/coercitivas foi pouco observada entre as práticas recebidas (4\%), mas esteve mais presente entre as utilizadas com seus filhos (16\%). As comparações entre proporções de práticas recebidas e utilizadas pelos pais revelam apenas uma diferença significativa entre as práticas indutivas $(p<0,05)$, indicando uma redução no uso dessas práticas pelos pais com seus filhos. Por fim, compararam-se as proporções de práticas, recebidas e utilizadas, entre mães e pais. Essa análise não revelou nenhuma diferença estatisticamente significativa.

Tabela 2. Porcentagem e Frequências de Práticas Educativas Recebidas e Utilizadas Segundo Mães (n=30) e Pais ( $\mathrm{n}=22)$

\begin{tabular}{|c|c|c|c|c|c|c|c|c|c|c|}
\hline & \multicolumn{4}{|c|}{ Mães } & \multicolumn{6}{|c|}{ Pais } \\
\hline & \multicolumn{2}{|c|}{ Recebidas } & \multicolumn{2}{|c|}{ Utilizadas } & \multirow[t]{2}{*}{$\mathrm{Z}$} & \multicolumn{2}{|c|}{ Recebidas } & \multicolumn{2}{|c|}{ Utilizadas } & \multirow[t]{2}{*}{ Z } \\
\hline & $\%$ & $f$ & $\%$ & $F$ & & $\%$ & $f$ & $\%$ & $f$ & \\
\hline Indutivas & 41 & 26 & 30 & 46 & 1,38 & 38,5 & 17 & 18,5 & 16 & $2,27^{*}$ \\
\hline Coercitivas & 53 & 34 & 56,5 & 87 & 0,30 & 50 & 22 & 65,5 & 57 & 1,60 \\
\hline Indutivas/coercitivas & 3,0 & 2 & 13,0 & 20 & $1,95^{*}$ & 4,5 & 2 & 16,0 & 14 & 1,49 \\
\hline Não interferência & 3,0 & 2 & 0,5 & 1 & 0,79 & 7,0 & 3 & - & 0 & 1,83 \\
\hline Total & 100 & 64 & 100 & 154 & & 100 & 44 & 100 & 87 & \\
\hline
\end{tabular}

$* \mathrm{p}<0,05 ; * * \mathrm{p}<0,01 ; * * * \mathrm{p}<0,001$ 


\section{Associação entre Práticas Recebidas e Utilizadas: a Transmissão Intergeracional Caso a Caso}

No que diz respeito às práticas recebidas $(n=49), 39 \%$ dos participantes relataram ter recebido predominantemente práticas coercitivas, em 34,5\% dos casos não houve predomínio de práticas, $24,5 \%$ relataram ter recebido um maior número de práticas indutivas e $2 \%$ práticas de não interferência. Já quanto às utilizadas com o próprio filho $(n=52), 54 \%$ dos participantes relataram não haver predominância de um tipo de prática educativa, $42 \%$ afirmaram utilizar predominantemente práticas coercitivas, apenas $2 \%$ apontaram práticas indutivas e $2 \%$ práticas indutivas e coercitivas combinadas.

Práticas recebidas e utilizadas foram associadas de modo a demonstrar se pais que receberam predominantemente determinada prática em sua criação, tendiam a repetir o mesmo modelo com seus próprios filhos. Essa análise foi realizada somente com as categorias de práticas coercitivas, indutivas e sem predomínio, uma vez que as demais apresentaram baixa ocorrência na amostra. Variáveis do tipo sim ou não foram criadas para cada prática educativa predominante recebida e utilizada e, dessa forma, análises de associação foram realizadas em separado para cada tipo de prática.

O teste qui-quadrado para as práticas coercitivas recebidas e utilizadas demonstrou não haver associação estatisticamente significativa entre essas variáveis $\left(\chi^{2}=0,258\right.$; $\mathrm{df}=1 ; p=0,61)$. Do total de pais que afirmaram ter recebido predominantemente práticas coercitivas (19 pais), menos da metade (nove pais) afirmaram manter o mesmo padrão com seus filhos. O teste também não apresentou associação significativa entre práticas indutivas recebidas e utilizadas $\left(\chi^{2}=\right.$ $0,331 ; \mathrm{df}=1 ; p=0,56)$, sendo que dos 12 pais que afirmaram ter recebido predominantemente práticas indutivas, nenhum deles manteve esse padrão com seus filhos. Por fim, também não se associaram de forma significativa as variáveis de práticas sem predominância $\left(\chi^{2}=0,377 ; \mathrm{df}=1 ; p=0,53\right)$. Dos 17 pais que afirmaram não ter havido qualquer predominância de práticas entre as recebidas, somente oito pais afirmaram ter mantido o mesmo padrão com seus próprios filhos.

\section{Análise Qualitativa das Práticas Educativas Recebidas e Utilizadas}

Com a análise qualitativa buscou-se identificar particularidades que não foram evidenciadas na análise quantitativa e que podem contribuir para a compreensão de como se dão os processos de transmissão intergeracional de práticas educativas parentais. Especialmente, buscou-se complementar a análise da transmissão intergeracional das práticas em nível individual, uma vez que as análises quantitativas tiveram como foco as mudanças intergeracionais no grupo como um todo, o que não necessariamente reflete a realidade de cada família.

Em muitos casos, tanto mães como pais denotaram preocupação em repetir com seus filhos o que julgaram bom da educação recebida de seus genitores: "Sempre o castigo, nunca bater. Tento pegar coisas do meu pai, da minha mãe que eu achei legal" (M6); "Eu procuro disciplinar minha filha do jeito que eu fui disciplinada. Dando liberdade, mas também mostrando que tem limite. Eu não tenho do que me queixar da minha educação, então eu vou usar o exemplo que eu tive" (M30). Ressalta-se que essa tentativa de reprodução não diz respeito a um único padrão de práticas educativas como sendo necessariamente o mais adequado, tais como no próximo exemplo em que foram elogiadas as práticas coercitivas recebidas: "A mãe era de dar puxão de orelha, de dar puxão de cabelo, de chamar atenção, colocar de castigo. Eu acho que castigo funciona bem" (M19); "Hoje dizem que não pode bater. Minha mãe me batia, meu pai me batia e nem por isso hoje eu sou uma pessoa cheia de traumas, cheia de problemas. Eu acho até que eu agradeço certas coisas que eles fizeram" (M28); "Apesar de ter apanhado muito, eu não consigo ver esse apanhar como uma forma ruim" (M16). Inclusive, uma mãe relatou admiração e pesar por não conseguir repetir as práticas recebidas com os próprios filhos: "Quando a gente era pequena, a gente tinha horário pra tudo. E ela [a mãe] era muito rigorosa. Eu acho até uma pena que eu não consegui pegar isso, porque eu gostaria de ter pego. Mas eu lembro que nós tínhamos hora pra acordar, hora pro café, hora pro lanche. Eu gostaria de ser assim hoje com ele, mas eu sou muito desleixada" (M3).

Contudo, alguns participantes evidenciaram preocupação em fazer diferente, em melhorar o que não consideravam adequado em sua educação, a exemplo dos relatos seguintes: "O meu pai era sempre assim, controlando tudo que eu fizesse, era uma coisa assim de sufocar e diálogo nunca tinha muito, porque eu pedia, às vezes, alguma explicação e a resposta era sempre assim: 'não, porque não e pronto'. Às vezes eu até me questiono [referindo-se às suas práticas com o próprio filho]: 'tá eu disse que não, mas por que não?' É que como eu fui criada também nada podia, então, às vezes, eu fico pensando assim: 'mas por quê?' Isso não vai fazer nenhum mal! Tá, deixa!” (M7); "Eles só me olhavam, eles não falavam nada. Eu já sabia que não era pra fazer aquilo que eu ia apanhar. Hoje eu converso com ele [referindo-se ao seu filho]. Ah! Eu pego ele pelo braço e falo com ele até ele entender que o tipo de coisa que ele tava fazendo não é bom pra ele" (P9); "Eu ficava bastante de castigo. Eu já tomei uns tapas também, mas acho melhor conversar e mostrar o que é certo e o que é errado" (M13).

Quando o padrão recebido foi predominantemente a não interferência, identificou-se uma tendência a buscar o uso tanto de práticas indutivas, quanto coercitivas: "Ah, eles sempre deixaram muito livre, eles apoiavam tudo, eles não eram de ficar forçando nada, forçar a estudar" (P14). Já com o seu filho comentou: "Falar, conversar bastante com ele, explicar o porquê (...) mas depois botei ele de castigo no quarto" (P14).

Alguns participantes identificaram um de seus genitores como sendo a figura mais marcante de autoridade, cujo padrão de práticas, segundo seu relato, acabaram por repetir na educação dos próprios filhos:

\footnotetext{
"Às vezes, o cara tenta imitar mesmo o pai da gente, eu acho que eu fui mais ou menos que nem agora, quando a gente era mais reprimido e coisa. O meu pai só falava uma ou duas vezes e pronto, ai a gente respeitava mais ele. A mãe não, a mãe falava, falava, dai eu falava: 'ah, mãezinha, não sei o quê'. Era mais afetuoso com ela e ela passava a mão por cima. Ele não! Ele era mais rígido" $(P 1)$.
} 
Esse pai, embora numa análise mais ampla, enquanto filho, tenha experimentado de seus genitores um padrão de práticas indutivas e coercitivas, revelou tendência ao uso de práticas coercitivas, característica que aparece como estando relacionada às práticas recebidas de seu pai.

Um dos pais entrevistados mencionou a situação de violência física e verbal, evidenciando o uso de práticas coercitivas por seu próprio pai: "Meu pai, porque fui mal na escola, me mandou embora de casa. Tomei pontapé, tive que me esconder embaixo da cama para não apanhar, dava de relho" (P2), padrão esse que revelou também utilizar com seu filho: "Com ele um castigo é perfeito. Se tu pegar ele e botar deitado na cama dele e só dizer pra ele sair de lá depois que ele pensar no assunto, é o que funciona melhor" (P2). Chama atenção a tentativa do participante em amenizar a intervenção coercitiva com seu filho, na medida em que, ainda que utilize a punição colocando o filho de castigo, pede que ele pense no que fez de errado, diferente de sua vivência com o próprio pai, que fazia uso mais frequente de punição física.

Outra situação, diz respeito à desvalorização das práticas educativas parentais recebidas devido a participante acreditar ter sido descuidado quando criança: "Não lembro de alguém ter me dado comida, eu sempre comi sozinha. Hora de banho, café sempre pronto, saía do banho, já tomava café e o resto sempre na rua, brincando. Olha, o que eu sei hoje da minha vida não foi minha mãe que me ensinou" (M25); ou em função de problemas mentais dos genitores "Ah, eu não sei realmente o que ela [mãe] pensava, porque ela tinha problemas. Geralmente ela entrava em crise nervosa, ela tinha problema mental, sabe?" (M19).

Além das questões de transmissão intergeracional, também foi possível observar a influência da prática exercida pelo cônjuge na escolha das suas próprias práticas educativas. Um exemplo em que se evidencia uma possível influência do cônjuge na opção por determinado padrão de práticas é encontrado a seguir, em que embora a mãe tenha recebido tanto práticas indutivas quanto coercitivas de seus genitores: "Eu nunca apanhei do meu pai, nunca meu pai encostou um dedo em mim, mas a mãe dava uns tapinhas na bunda, uns gritos" (M2), referiu usar um padrão mais coercitivo com o filho: "Eu sou gritona mesmo, eu grito, esperneio, mas pra bater nele é mais complicado. Eu ameaço e não bato" (M2). Tal achado pode estar relacionado à vivência do cônjuge que recebeu práticas predominantemente coercitivas: "Meu pai era rígido, chegava a ser até severo assim... Cara, até de relho eu apanhei” (P2).

Outro aspecto peculiar na análise dos relatos diz respeito à ausência física de genitores como interferindo nas práticas recebidas "A mãe faleceu muito cedo e o pai faleceu quando eu tinha 16 anos. O pai conseguiu criar quatro filhos homens sozinho, por um período de 10 anos sem nunca encostar a mão em nenhum de nós. Meu pai dizia: 'vou falar uma só vez, nós somos amigos"” (P4), e, por conseguinte, nas práticas utilizadas: "Algum tempo atrás, em algumas oportunidades, eu dei uns tapas na bunda dela, mas mesmo sabendo que aquilo não tava machucando ela fisicamente, não era agradável pra mim" (P4). Nesse contexto, as práticas utilizadas pelo cônjuge parecem ser de especial relevância. Nesse caso, por exemplo, o cônjuge refere uso de práticas ora indutivas, ora coercitivas: "Ah, eu tento corrigir, dependendo da situação eu brigo, dependendo da situação eu converso" (M4).

O próprio temperamento do participante foi descrito por uma das mães como influenciando no uso de determinada prática, ainda que se observe uma tendência em tentar inicialmente reproduzir a prática recebida: "Tu podia fazer o que tu queria, mas tu tinha regras pra cumprir" (M15); enquanto que com sua filha destaca: "Olha, eu acho que a conversa é a primeira delas. É o explicar as coisas. Tem horas que isso me toca de frente e aí eu fico explosiva, fico braba e xingo e grito e bato pé, né?" (M15).

Por fim, foi destacada também a influência do temperamento da criança nas práticas educativas utilizadas, de modo que essa variável contribuiu para explicar a mudança no padrão entre a educação recebida e a utilizada: "Eles conversavam. O meu pai nunca me bateu, mais era conversa mesmo. Era uma educação bem em cima, eles não deixavam solto por aí. Eram bem rígidos" (M10); enquanto com seu filho destacou que: "Eu tento conversar com ele, porque ele é muito nervoso, qualquer coisinha ele chora e grita. A gente pede pra ele se acalmar e falar direito. Aí a gente vai explicar, mas tem hora que não adianta" (M10). Já um pai relatou: "Meu pai era um pouco mais durão, mas minha mãe, geralmente, era na conversa. Conversava bastante com a gente. Meu pai falava que ia ter uma conversinha, mas a conversinha dele era uma cinta branca" (P7). O mesmo pai relata a dificuldade que às vezes possui com seu próprio filho: "Seria o ideal tu conversar com a criança, a criança entender e ficar por isso, mas geralmente não é isso que acontece. Eu até converso bastante, converso pra explicar a situação. Às vezes, resolve. Agora, tem vezes que não dá, a teimosia é grande e tu acaba punindo ou dando um tapa" (P7).

\section{Discussão}

As práticas educativas parentais constituem fator de importante influência no desenvolvimento socioemocional de pais e filhos. Nesse sentido, a análise de questões de transmissão intergeracional, que constituiu objetivo do presente estudo, assume especial relevância. Em termos gerais, os resultados obtidos corroboram a literatura, que descreve efeitos entre leves e moderados no que diz respeito à transmissão intergeracional de práticas educativas em diferentes populações (Conger et al., 2009).

Considerando os resultados do primeiro bloco de análises, que contemplou a amostra de maneira geral, a constatação de que houve uma manutenção de práticas coercitivas entre as gerações reforça os resultados de estudos nacionais e internacionais que destacaram a continuidade de comportamentos agressivos e práticas educativas inconsistentes (Bailey et al., 2009; Hennig, 2008; Kerr et al., 2009) como associadas às memórias de estilos parentais inadequados quando crianças (Hennig, 2008). Destaca-se, no entanto, que, nessa etapa, o foco das análises foram as possíveis mudanças ou continuidades nas práticas educativas entre gerações e não necessariamente nos casos individuais. Assim, esses resultados indicam que, ao longo do tempo, as práticas coercitivas parecem ter se mantido como estratégia de socialização das crianças, porém também fornecem indícios de que atualmente os pais vêm 
fazendo, com maior frequência, uso combinado de práticas indutivas e coercitivas, o que pode sugerir mudança histórica nas concepções de como criar adequadamente os filhos entre as gerações (Benincá \& Gomes, 1998; Biasoli-Alves, 1997; Fonseca, 2005; Weber et al., 2006).

Em contrapartida, no segundo bloco de análises, em que foram examinadas as práticas educativas caso a caso, não se verificaram resultados homogêneos, ou seja, a transmissão das práticas foi constatada somente para alguns casos, mas não para a maioria deles. Tal achado fortalece a concepção de que as práticas educativas parentais são um processo recíproco que envolve características da criança e de seus pais, conforme já havia sido sugerido por autores nacionais e internacionais (Belsky, 1984; Biasoli-Alves, 1997). Nesse sentido, a transmissão intergeracional das mesmas também é influenciada por outros fatores, não envolvendo somente a reprodução para com os filhos dos padrões recebidos quando criança, ainda que estes levem à construção de modelos, conscientes ou não, sobre o que deve ser seguido ou evitado nas relações posteriores (Ângelo, 1995). Além disso, tal achado evidencia que a forma como as pessoas avaliam a maneira como foram criadas influencia a continuidade ou descontinuidade das práticas educativas (Shaffer et al., 2009), sendo que as experiências vivenciadas durante a própria criação não são inevitavelmente repetidas (Belsky et al., 2009), dando espaço à busca pela replicação ou pela correção de experiências prévias na relação com os filhos (Byng-Hall, 1990).

Isso pode ser observado especialmente nas análises qualitativas, em que muitos dos genitores denotaram a reprodução de padrões coercitivos, ainda que estes fossem relatados como evitados, na medida em que eram relacionados à ideia de vivência de sofrimento quando crianças, corroborando os achados de estudos internacionais anteriores (Bailey et al., 2009; Conger et al., 2003; Kim, 2009; Neppl et al., 2009). Por outro lado, alguns genitores mencionaram que, mesmo tendo associado memórias desagradáveis às práticas educativas coercitivas vivenciadas enquanto criança, faziam uso eventual das mesmas para com seus filhos, por acreditarem que não foram nocivas a eles e, portanto, não seriam para os filhos. Outro aspecto importante descrito na literatura e evidenciado pelos participantes diz respeito ao próprio temperamento dos pais, bem como o da criança, como uma influência no uso de determinada prática (Brody, 2004), mesmo que se observe tendência em tentar inicialmente reproduzir a prática recebida.

Em consonância com a literatura, os resultados do presente estudo evidenciaram ainda a aprendizagem de práticas ou habilidades parentais junto a outras figuras que não apenas os próprios pais, em especial o cônjuge (Capaldi et al., 2003). Nesse sentido, entre os casos analisados, pode-se perceber que a congruência de práticas em relação à criança não raramente se sobrepôs aos relatos de práticas recebidos na família de origem de um dos cônjuges. Nessa mesma direção, outro aspecto peculiar na análise dos relatos diz respeito à ausência dos genitores como interferindo nas práticas recebidas e utilizadas. Nesse contexto, as práticas utilizadas pelo cônjuge parecem ser de especial relevância.

Vale destacar que a complexidade da transmissão intergeracional das práticas educativas pode ser evidenciada neste estudo principalmente em função do método misto de análise empregado, o qual envolveu inicialmente uma abordagem quantitativa e, em seguida, uma qualitativa. Essa escolha metodológica foi realizada no decorrer do processo de análise, uma vez que as primeiras análises quantitativas forneceram indicativos para a compreensão da transmissão entre gerações, mas não sobre a transmissão nos casos individuais.

Nesse sentido, considera-se que uma contribuição importante do estudo foi a combinação de métodos de análise, que permitiu captar diferentes facetas do mesmo fenômeno (Creswell, 1994). Por exemplo, num nível mais amplo, os resultados indicaram a manutenção das práticas coercitivas entre as gerações, bem como o aumento na utilização de práticas que combinam estratégias indutivas e coercitivas. Já quando se analisou a transmissão intergeracional caso a caso, as análises revelaram que apenas em, aproximadamente, metade dos casos houve a transmissão dos padrões interativos. Por fim, as análises qualitativas indicaram ainda que diversas variáveis poderiam explicar a transmissão ou não das práticas, tais como o temperamento da criança, a reflexão crítica que os pais fazem em relação à forma como foram criados e as práticas utilizadas pelo cônjuge.

A utilização de categorias baseadas na literatura sobre o tema também se mostrou como uma estratégia relevante, considerando que isso permitiu a comparação destes achados com outros estudos que investigaram as práticas educativas indutivas e coercitivas. Assim, sugere-se que novos estudos possam avançar na compreensão da transmissão intergeracional, baseando-se em categorias semelhantes, porém inovando metodologicamente, de forma a transpor algumas das limitações deste estudo, como a forma com que foram coletados os dados sobre as práticas educativas da geração mais antiga (dos avós das crianças). Utilizou-se uma entrevista retrospectiva com os pais, na qual eles relatavam a forma com que foram criados a partir de suas lembranças sobre a infância. Essa técnica implica em dados que podem não refletir exatamente o estilo interativo da primeira geração, já que conta somente com a lembrança de fatos mais marcantes para os participantes. No entanto, conforme descreveu Van IJzendoorn (1992), estudos já demonstraram a importância de considerar a forma como a experiência foi internalizada pelo sujeito. Assim, é possível supor que o que exerce influência sobre o comportamento dos pais não é apenas a experiência real com seus próprios pais, mas a forma como a mesma foi elaborada e, consequentemente, a forma como é relembrada no momento em que o sujeito se torna mãe ou pai, justamente o que é acessado por estudos retrospectivos. Além disso, deve-se destacar que os resultados obtidos por estudos retrospectivos têm sido corroborados por estudos prospectivos (Neppl et al., 2009; Weber et al., 2006). Assim, apesar de suas possíveis limitações, os relatos de lembranças parecem constituir um meio válido de se aproximar das práticas educativas vivenciadas na infância.

Por fim, sugere-se que futuros estudos incluam outras variáveis que podem mediar a transmissão intergeracional das práticas educativas. Por exemplo, características individuais dos pais e avós (personalidade, saúde mental), características relacionais entre pais-avós e pais-criança (relações de apego), características individuais da criança (temperamento, sexo), e características contextuais (crenças, valores e costumes de criação em diferentes grupos culturais). 


\section{Referências}

Alvarenga, P., \& Piccinini, C. A. (2003). Práticas educativas maternas e a interação entre mães e crianças com problemas de externalização. Aletheia, 17/18, 7-20.

Alvarenga, P., \& Piccinini, C. A. (2001). Práticas educativas maternas e problemas de comportamento em pré-escolares. Psicologia: Reflexão e Crítica, 14, 449-460.

Ângelo, C. (1995). A escolha do parceiro. In M. Andolfi, C. Ângelo, \& C. Saccu (Eds.), A crise do casal (pp. 47-57). São Paulo: Summus.

Bailey, J. A., Hill, K. G., Oesterle, S., \& Hawkins, J. D. (2009). Parenting practices and problem behaviors across three generations: monitoring, harsh discipline, and drug use in the intergenerational transmission of externalizing behavior. Developmental Psychology, 45, 1214-1226.

Bandura, A. (1977). Social learning theory. New York: General Learning Press.

Bardin, L. (1977). Análise de conteúdo. Lisboa: Edições 70.

Belsky, J. (1984). The determinants of parenting: a process model. Child Development, 55, 83-96.

Belsky, J., Conger, R., \& Capaldi, D. M. (2009). The intergenerational transmission of parenting: introduction to special section. Developmental Psychology, 45, 1201-1204.

Belsky, J., Jaffee, S. R., Sligo, J., Woodward, L., \& Silva, P. A. (2005). Intergenerational transmission of warm-sensitivestimulating parenting: a prospective study of mothers and fathers of 3-years-olds. Child Development, 76, 384-396.

Benincá, C. R. S., \& Gomes, W. B. (1998). Relatos de mães sobre transformações familiares em três gerações. Estudos de Psicologia (Natal), 3, 177- 205.

Biasoli-Alves, Z. M. M. (1997). Famílias brasileiras do século XX: Os valores e as práticas de educação da criança. Temas em Psicologia, 3, 33-49.

Boszormenyi-Nagy, I., \& Spark, G. M. (2008). Lealtades invisibles: Reciprocidad en terapia familiar intergeracional. Buenos Aires: Amorrortu. (Trabalho original publicado em 1973)

Bowlby, J. (2001). Formação e rompimento dos laços afetivos. São Paulo: Martins Fontes. (Trabalho original publicado em 1982)

Brody, G. H. (2004). Siblings' direct and indirect contributions to child development. Current Directions in Psychological Sciences, 13, 124-126.

Byng-Hall, J. (1990). Attachment theory and family therapy: A clinical view. Infant Mental Health Journal, 11, 228-236.

Capaldi, D. M., Pears, K., Patterson, G. R., \& Owen, L. D. (2003). Continuity of parenting practices across generations in an atrisk sample: A prospective comparison of direct and mediated associations. Journal of Abnormal Child Psychology, 31, 127-142.

Conger, R. D., Belsky, J., \& Capaldi, D. M. (2009). The intergenerational transmission of parenting: closing comments for the special section. Developmental Psychology, 45, 1276-1283.

Conger, R. D., Neppl, T., Kim, K. J., \& Scaramella, L. (2003). Angry and aggressive behavior across three generations: A prospective, longitudinal study of parents and children. Journal of Abnormal Child Psychology, 31, 143-160.

Creswell, J. W. (1994). Research design: Qualitative \& quantitative approaches. Thousand Oaks, CA: Sage.
Falcke, D., \& Wagner, A. (2005). A dinâmica familiar e o fenômeno da transgeracionalidade: Definição de conceitos. In A. Wagner (Ed.), Como se perpetua a família? A transmissão dos modelos familiares (pp. 25-46). Porto Alegre: EDIPUCRS.

Falcke, D., Wagner, A., \& Mosmann, C. (2005). Passando a história a limpo: O impacto das experiências da família de origem na conjugalidade. In A. Wagner (Ed.), Como se perpetua a família? A transmissão dos modelos familiares (pp. 67-80). Porto Alegre: EDIPUCRS.

Fonseca, C. (2005). Concepções de família e práticas de intervenção: Uma contribuição antropológica. Saúde e Sociedade, 14(2), 50-59.

Grusec, J. E., \& Lytton, H. (1988). Socialization and the family. In J. E. Grusec, \& H. Lytton (Ed.), Social development: History, theory and research (pp. 161-210). New York: Springer-Verlag.

Hennig, F. (2008). Relação entre práticas educativas parentais e memórias de cuidado na infância. Dissertação de Mestrado, Universidade Federal de Santa Catarina, Florianópolis.

Hoffman, M. L. (1975). Moral internalization, parental power and the nature of parent-child interaction. Developmental Psychology, 11, 228-239.

Hoffman, M. L. (1979). Development of moral thought, feeling and behavior. American Psychologist, 34, 958-966.

Hoffman, M. L. (1994). Discipline and internalization. Developmental Psychology, 30, 26-28.

Hops, H., Davis, B., Leve, C., \& Sheeber, L. (2003). Crossgenerational transmission of aggressive parent behavior: A prospective mediational examination. Journal of Abnormal Child Psychology, 31(2), 161-169.

Imber-Black, E. (1994). Segredos na família e na terapia familiar: Uma visão geral. In E. Imber-Black (Ed.), Os segredos na família e na terapia familiar (pp. 15-39). Porto Alegre: Artes Médicas.

Kerr, D. C. R., Capaldi, D. M., Pears, K. C., \& Owen, L. D. (2009). A prospective three generational study of fathers' constructive parenting: Influences from family of origin, adolescent adjustment, and offspring temperament. Developmental Psychology, 45, 1257-1275.

Kim, J. (2009). Type-specific intergenerational transmission of neglectful and physically abusive parenting behaviors among young parents. Children and Youth Services Review, 31, 761767.

Laville, C., \& Dione, J. (1999). A construção do saber: Manual de metodologia em ciências humanas. Porto Alegre: Artmed.

Marin, A. H., Piccinini, C. A., \& Tudge, J. (2011). Estabilidade e mudança nas práticas educativas maternas e paternas ao longo dos anos pré-escolares da criança. Psicologia: Reflexão e Crítica, 24, 71-79.

Marin, A. H. (2009). Estabilidade e mudança nas práticas educativas maternas e paternas ao longo dos anos préescolares e sua relação com a competência social infantil. Tese de Doutorado, Universidade Federal do Rio Grande do Sul, Porto Alegre.

Miermont, J. (1994). Dicionário de terapias familiares: Teoria e prática. Porto Alegre: Artes Médicas.

Neppl, T. K., Conger, R. D., Scaramella, L. V., \& Ontai, L. L. (2009). Intergenerational continuity in parenting behavior: Mediating pathways and child effects. Developmental Psychology, 45, 1241-1256. 
Newcombe, N. (1999). Socialização no cenário da família. In N. Newcombe (Ed.), Desenvolvimento infantil: Abordagem de Mussen (pp. 336-363). Porto Alegre: Artes Médicas.

Nichols, M. P., \& Schwartz, R. C. (1998). Primeiros modelos e técnicas básicas: processos de grupo e análises das comunicações. In M. P. Nichols, \& R. C. Schwartz (Eds.), Terapia familiar: Conceitos e métodos (pp. 153-185). Porto Alegre: Artes Médicas.

Oliveira, E. A., Marin, A. H., Pires, F. B., Frizzo, G. B., Ravanello, T., \& Rossato, C. (2002). Estilos parentais autoritário e democrático-recíproco intergeracionais, conflito conjugal e comportamentos de externalização e internalização. Psicologia: Reflexão \& Crítica, 15, 1-11.

Piccinini, C. A., Tudge, J. R., Lopes, R. C., \& Sperb, T. (1998/2009). Projeto Longitudinal de Porto Alegre: da Gestação à Escola. (Projeto não publicado). Universidade Federal do Rio Grande do Sul, Porto Alegre.

Shaffer, A., Burt, K. B., Obradovic, J., Herbers, J. E., \& Masten, A. S. (2009). Intergenerational continuity in parenting quality: The mediating role of social competence. Developmental Psychology, 45, 1227-1240.

Steinberg, L. (2000). The family at adolescence: Transition and transformation. Journal of Adolescent Health, 27, 170-178.
Tudge, J. R. H. (1994). The cultural ecology of young children interview. Unpublished instrument, University of North Carolina. Greensboro, NC.

Vitali, I. L. (2004). Como nossos pais? A transmissão intergeracional dos estilos parentais. Dissertação de Mestrado, Universidade Federal de Santa Catarina, Florianópolis.

Van IJzendoorn, M. H. (1992). Intergenerational transmission of parenting: A review of studies in non-clinical populations. Developmental Review, 12, 76-99.

Weber, L. N. D., Selig, G. A., Bernardi, M. G., \& Salvador, A. P. V. (2006). Continuidade dos estilos parentais através das gerações: transmissão intergeracional dos estilos parentais. Paidéia, 16(35), 407-414.
Recebido em 06.09.2011

Primeira decisão editorial em 11.05.2012

Versão final em 21.06.2012

Aceito em 25.07.2012 